\title{
Changes on surface morphology of corn starch blend films
}

\author{
Maria Alberta Araújo, ${ }^{1,2}$ António M. Cunha, ${ }^{3}$ Manuel Mota $^{2}$ \\ ${ }^{1}$ Escola Superior de Tecnologia e Gestão, IPVC, Avenida Atlântico, Viana do Castelo 4900-348, Portugal \\ ${ }^{2}$ IBB-Institute for Biotechnology and Bioengineering, Centre for Biological Engineering, Universidade do Minho, \\ Campus de Gualtar 4710-057 Braga \\ ${ }^{3}$ Department of Polymer Engineering, Institute for Polymers and Composites, Universidade do Minho, Campus de Azurém, \\ Guimarães 4800-058, Portugal
}

Received 24 October 2008; revised 17 July 2009; accepted 22 October 2009

Published online 11 March 2010 in Wiley InterScience (www.interscience.wiley.com). DOI: 10.1002/jbm.a.32725

\begin{abstract}
This study aims at evaluating the influence of enzymatic degradation solution on the surface morphology and thermal properties of a poly(ethylene-vinyl alcohol) copolymer-corn starch thermoplastic blend (SEVA-C), as a function of immersion time. To perform this study, three different batches were assessed using SEVA-C samples of different thicknesses and a fixed weight of $1.6 \mathrm{~g}$, immersed in $\alpha$-amylase ( $50 \mathrm{u} / \mathrm{L}$ ) up to 90 days at $37^{\circ} \mathrm{C}$. TGA, contact angle measurements, scanning electron microscopy (SEM) and atomic force microscopy (AFM) techniques were used. Three degradation mechanisms are considered in these systems:
\end{abstract}

namely, mass loss due to plasticizer leaching (glycerol), starch enzymatic cleavage, and synthetic polymer fractions degradation. Enzymatic hydrolysis of the starch fraction and subsequent leaching from the internal bulk structure led to an increase in surface porosity, pore size, roughness, and to the development of small pits throughout the surface, as observed by SEM and AFM. $\odot 2010$ Wiley Periodicals, Inc. J Biomed Mater Res Part A: 94A: 720-729, 2010

Key Words: MATERBI 1128RR, surface analysis, starch blend, alpha-amylase degradation, biomaterial

\section{INTRODUCTION}

The use of degradable polymeric materials as bone fillers or in the fixation of some fractures is becoming common procedure. ${ }^{1-3}$ Their utilization may include devices such as surgical sutures, several types of non permanent implants, and drug carriers in several specific drug delivery systems. Polymers with controlled behavior are required for temporary applications in repair and regeneration of healing tissues. In such applications, the biodegradation and consequently the associated mechanical properties of the polymer should progress as a function of implantation time providing high strength for tissue fixation in the early stages, followed by a gradually and controlled load transfer to the tissue as it heals. ${ }^{4}$

The material modulus decay and the gradual load transfer to the healing bone should be associated to the desired absorption of the implant material to avoid the removal process. 5,6

One aspect that is very important for biodegradable materials is their biocompatibility; this means that the material must degrade without eliciting an inflammatory response or an extreme immunogenicity or cytotoxicity. ${ }^{7} \mathrm{~A}$ potential disadvantage of using biodegradable polymers in biomedical applications is the eventual toxicity of the degradation products, which are aimed at being non toxic leachables and easy metabolized molecules and subsequently be assimilated or excreted via the kidneys and lungs. ${ }^{8}$

Starch is a fully biodegradable material, highly available, and can be easily modified, constituting, therefore, a poten- tial biomaterial. On the other hand, starch itself has poor mechanical properties, and it is difficult to process. Moreover, pure starch products and even those derived from the so-called thermoplastic starch (starch with disrupted granular structure) are usually brittle and moisture sensitive, thus strongly limiting their potential fields of application. Several strategies can be followed to achieve the desired material "character," including polymer synthesis/molecular design, polymer blending, chemical modification, among others. ${ }^{9}$

Starch-based polymers are being considered as an alternative to the currently used bioresorbable biomaterials, ${ }^{10-15}$ as they exhibit a range of properties within the typical biomedical requirements, ${ }^{6,16}$ such as bone replacement implants, ${ }^{6}$ bone cements, ${ }^{17}$ drug delivery systems, ${ }^{18}$ and tissue engineering scaffolds. ${ }^{19}$ In fact, due to their compounding and processing versatility, they can exhibit a range of properties analogous to natural bone as well as biocompatible behavior already demonstrated by in vitro ${ }^{20,21}$ and in vivo studies. ${ }^{22}$ The systems that have been most studied are blends of starch with ethylene-vinyl alcohol copolymer (SEVA-C), cellulose acetate, poly( $\varepsilon$-caprolactone), and poly(lactic acid). ${ }^{23}$ It has been shown that these blends can associate a envisaged degradable behavior with an interesting mechanical performance.

Starch is a polysaccharide comprising a-D-glucose units, which can be organized to form two distinct molecules, amylose and amylopectin. A possible advantage of using polysaccharide-based biomaterials is that they may act as 
analogs of polysaccharides present in vivo and adopt their roles.

These thermoplastic starches blends include complexes with synthetic copolymers containing hydrophylic and hydrophobic units (i.e. copolymers of vinylalcohol). The respective molecular structure has complex physical and chemical interactions resulting from a interpenetrated network between the starch and the ethylene-vinyl alcohol phases. $^{6,24}$

In fact, different microstructures can be observed in starch/vinyl-alcohol copolymers, ${ }^{25}$ from droplet to layer-like morphologies, depending on the different hydrophilicity of the synthetic copolymer, on starch type, on copolymer composition, and the complex formed between amylose and the synthetic molecules that will influence also the mechanical properties and degradation modes of the respective products. ${ }^{26}$ Second derivative IR studies suggest for the amylose configuration a six-folded single helix identified as a "V" structure. ${ }^{27}$ The biodegradation rate of starch in these materials is inversely proportional to the content of amylose/ vinyl alcohol copolymer complex.

The model proposed to describe these interactions has been proposed considering large individual amylopectin molecules interconnected at several points per molecule as a result of hydrogen bonds and entanglements by chains of amylose/vinyl alcohol copolymer V complexes.

This structure has been defined in the literature as "interpenetrated" and makes starch completely insoluble. ${ }^{27}$

The main enzymes involved in starch hydrolysis are $\alpha$ amylase, $\beta$-amylase, glucoamylase, $\alpha$-glucosidase, and other debranching enzymes. $\alpha$-Amylase is an endo-specific enzyme that catalyses the hydrolysis of $\alpha-1,4$-glycosidic linkages of starch to glucose, maltose, and maltodextrins, reducing the molecular size of starch. It is also important to notice that $\alpha$-amylase can be found not only in saliva but also in human blood. ${ }^{28,29}$

Enzymatic hydrolysis of native starch is a reaction in which enzyme needs first to diffuse into the matrix and to bind to the solid substrate before breaking the glycosidic linkages. Although both the enzyme binding and the product released from solid substrates affect the overall rate of hydrolysis, the substrate structure usually dominates the reaction rate as it affects enzyme diffusion (due to starch granule porosity), binding, and bond cleavage. ${ }^{30,31}$

The degradation has been described to proceed in two further stages. First, water diffuses into the structure and swelling the structure, second, it binds to the starch regions, as penetration is easier than in the highly densely packed crystalline phase, followed by the hydrolytic degradation of the starch regions. A further stage starts after a significant part of the starch has been removed and involves the slow penetration of the water in the semicrystalline domains, following the increase in pores size as a result of chain scission. If hydrolysis is allowed to continue, with the water progressing to the inner zones of the test specimen, the crystalline parts may be also affected. ${ }^{28,29,32}$

This article reports the observed changes on surface structures during ageing, under normal human body tem- perature $\left(37^{\circ} \mathrm{C}\right)$ in presence of alpha-amylase and evaluates how the degradation of these starch-based biomaterials is affected by the hydrophobic and hydrophilic character of the respective surface. The surface morphology of the scaffolds was characterized by measurements of surface contact angles, surface energy, and scanning electron microscopy.

\section{MATERIALS AND METHODS \\ Materials}

The material used was a thermoplastic blend of corn starch with a poly(ethylene-vinyl alcohol) copolymer (60/40 mol/ mol), SEVA-C, supplied by Novamont, Italy (MATER-BI 1128RR). The blend has a melt flow index value of $0.71 \mathrm{~g} /$ $10 \min \left(170^{\circ} \mathrm{C}, 49 \mathrm{~N}\right)$.

The typical amount of corn starch in this commercially available blend is $50-60 \%$ (wt \%) composed of $70 \%$ of amylopectin and $30 \%$ of amylose. Three different batches were tested, using SEVA-C of different controlled thickness $(0.15$ and $0.5 \mathrm{~mm}$ ).

These commercial materials were supplied in granule form, and films were prepared by blown extrusion to produce different controlled thicknesses. In this melt-based processing, the material is extruded through a tubular die and immediately blown using compressed air. The result is the formation of a film balloon that stretches biaxially the film after the die exit. The final thickness of the film is controlled by the amount of air insufflated into the balloon, as the increase of its diameter is followed by a thinning of film. This technique is a widely used in the industry as it enables an accurate control of the thickness over a wide dimensional range.

Two batches consist of films of SEVA-C of 0.15 and 0.5 $\mathrm{mm}$ thickness, using always the same weight of $1.6 \mathrm{~g}$. To perform the same fixed weight of $1.6 \mathrm{~g}$, two films of $0.5 \mathrm{~mm}$ were used in one batch, and four films of $0.15 \mathrm{~mm}$ were used in another batch, according with Figure 1.

Comparing with the other batches where square plates of $30 \times 30 \times 2 \mathrm{~mm}$ were used, the surface area corresponded to 10 and 20 times $(0.5$ and 0.15 films with 95 $\mathrm{cm}^{2}$ and $190 \mathrm{~cm}^{2}$, respectively) the surface area of the other batch (square sectioned plates of $30 \times 30 \times 2 \mathrm{~mm}$ with 10 $\mathrm{cm}^{2}$ ). Figure 2 detailed the form of the three samples in each container (volume $50 \mathrm{~cm}^{3}$ ), square plate (a) and films of different thicknesses ( $b$ and $c$ ).

SEVA-C samples were weighed and immersed up to 90 days at $\mathrm{pH} 7.4$ and placed in a thermostatted immersion circulator $\left(37^{\circ} \mathrm{C} \pm 1^{\circ} \mathrm{C}\right)$ in individual containers (volume $\sim 50$ $\mathrm{cm}^{3}$ ) under continuous stirring (150 r.p.m.) with a Hank's balanced salt solution (HBSS) and with $\alpha$-amylase $50 \mathrm{u} / \mathrm{L}$ (from human saliva, Sigma reference A0521) to roughly simulate the hydration conditions in the human body, when the materials are implanted. The enzyme solution had an activity of $0.35 \mathrm{mg} / \mathrm{U} / \mathrm{min}$ at $\mathrm{pH} 6.9$ and $20^{\circ} \mathrm{C}$ per gram of soluble starch $(1 \% \mathrm{w} / \mathrm{v})$. To stabilise $\alpha$-amylase, $1 \mathrm{mM}$ calcium chloride was used.

HBSS has ion concentrations similar to those of human blood plasma. Control samples contained HBSS without enzyme. Samples weight were recorded and used to 

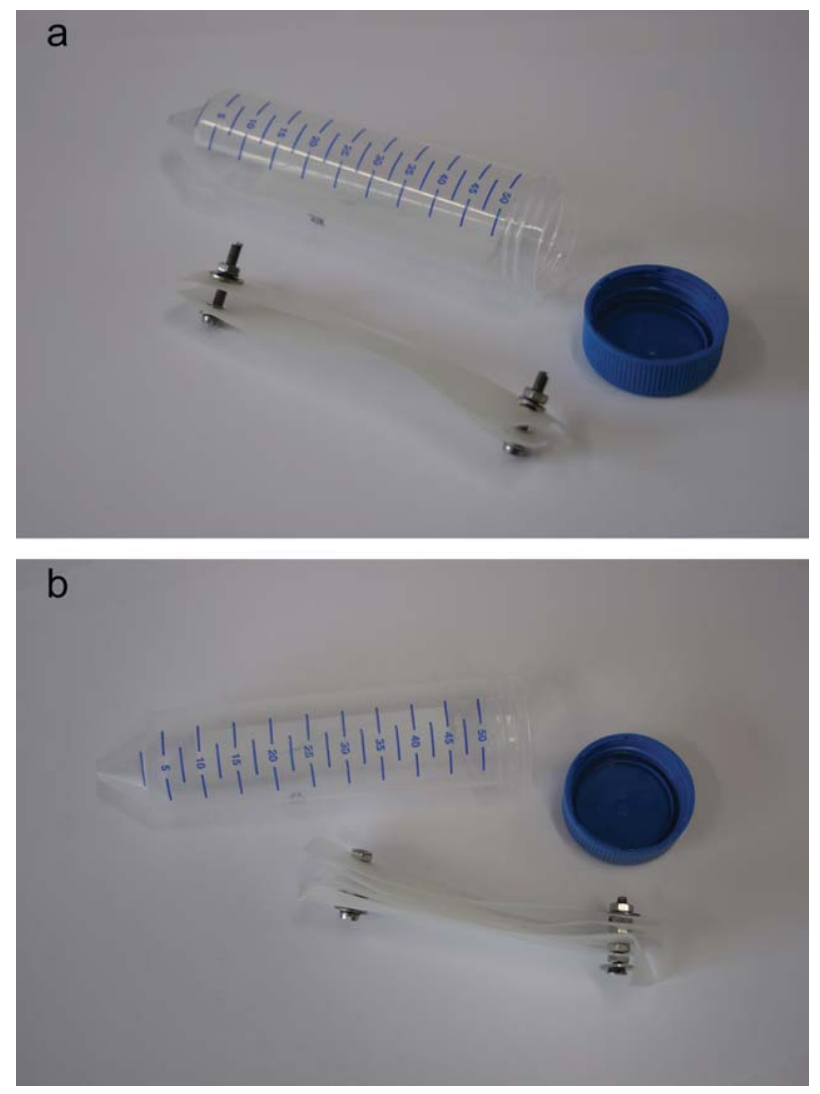

FIGURE 1. Batches using films of (a) $0.5 \mathrm{~mm}$ (two films) and (b) 0.15 $\mathrm{mm}$ (four films) thicknesses with $1.6 \mathrm{~g}$ weight. [Color figure can be viewed in the online issue, which is available at www. interscience.wiley.com.]

determine the mass percentage before and after the enzymatic degradation.

Squared plates and films were used in in vitro degradation experiments under strictly sterile conditions in a laminar flux chamber. Discs of $10 \mathrm{~mm}$ diameter and $1 \mathrm{~mm}$ thickness were used for scanning electron microscopy (SEM) and atomic force microscopy (AFM) surface morphology characterization. Samples were sterilized by autoclaving in an atmosphere of 10/90 mixture of ethylene oxide (EtO) and carbon dioxide $\left(\mathrm{CO}_{2}\right)$, with a cycle time of $20-22 \mathrm{~h}$ at a working temperature of $45^{\circ} \mathrm{C}$ and a chamber pressure of $180 \mathrm{kPa}$.

Enzyme activity (alpha-amylase) was also evaluated during 90 days of immersion and demonstrating a mean value of $0,35 \mathrm{mg}$ gluc/unit/min. The enzyme activity was followed during the degradation trials, to evaluate any deactivation throughout the assays, using the dinitrosalicylic acid method. ${ }^{33}$ The enzyme activity was expressed as mg glucose/unit/min for each enzyme concentration as a function of the immersion time.

End-products of degradation such as maltose and maltodextrins demonstrate no inhibiting effect on the enzyme activity.

\section{Analytical methods}

Glycerol quantification. The glycerol used as a plasticizer on the blend amount was quantified in the degradation sol- utions by High performance liquid chromatography (HPLC). HPLC with 830-RI (Jasco, Japan) refraction index detection and a 880-PU pump (Jasco) was used to separate glycerol from the degradation solutions. A Chrompack Ca column at $90^{\circ} \mathrm{C}$ with ultra-pure water as eluent $(0.5 \mathrm{~mL} / \mathrm{min})$ was kept at a $6500-7000 \mathrm{kPa}$ pressure. Eluent was filtered through a $0.22 \mu \mathrm{m}$ sterilized membrane previously degassed with helium and kept in a container to preclude contamination by airborne bacteria or fungi. Samples were also filtered through $0.22 \mu \mathrm{m}$ filters. Three replica of each sample were analyzed. A standard curve was obtained using different standard concentrations.
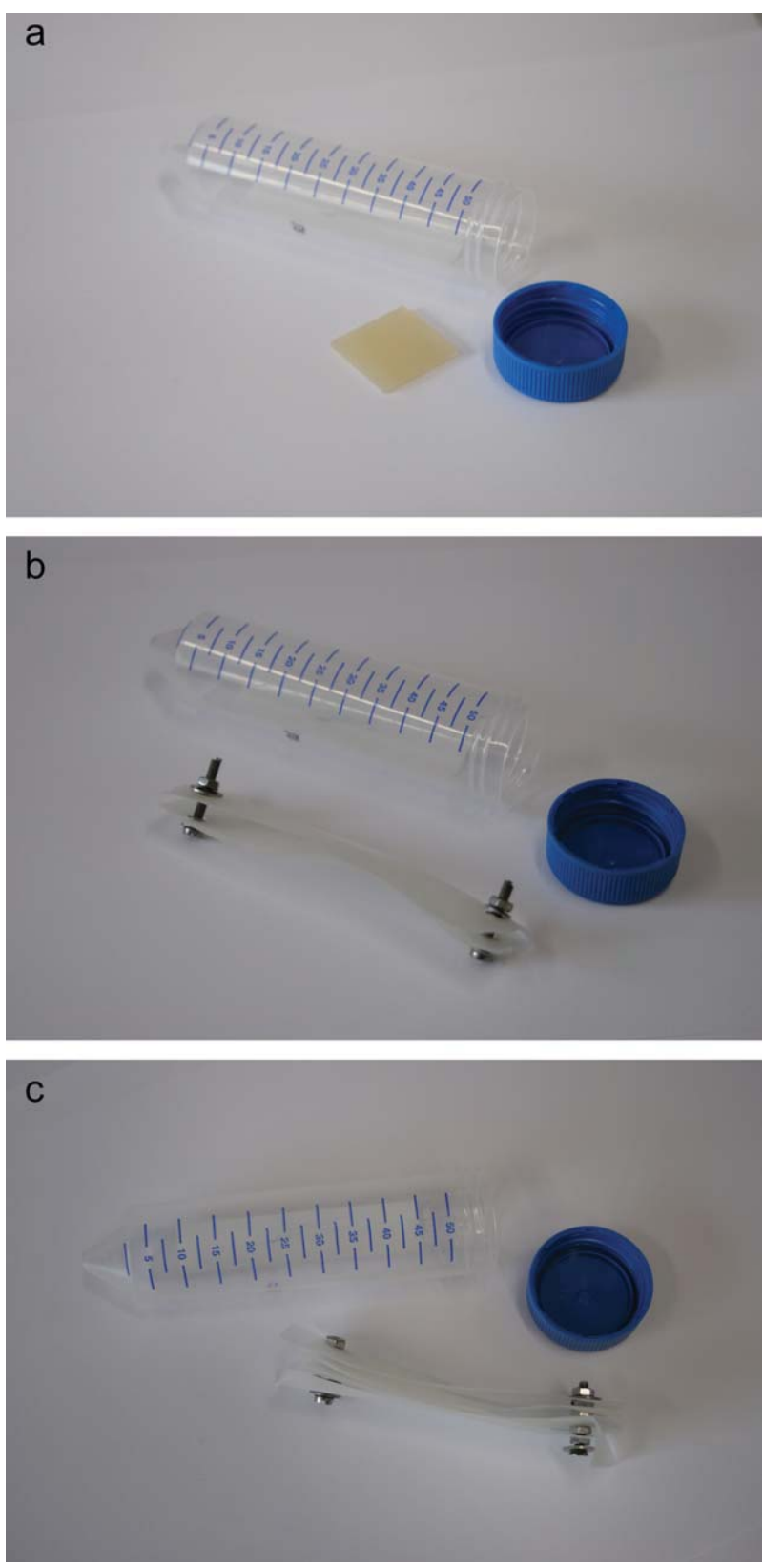

FIGURE 2. Setup of the samples in each assay. (a) Squared plate, (b) two films, and (c) four films. [Color figure can be viewed in the online issue, which is available at www.interscience.wiley.com.] 
Thermogravimetric analysis. Thermogravimetric analysis (TGA) was used to quantify the degradation extension of each component on the blend, as a function of immersion time, by comparison with the respective components of the blend (starch, glycerol, and EVAL).

A TGA-50 Shimadzu thermogravimetric equipment was used under the following conditions: heating rate of $10^{\circ} \mathrm{C} / \mathrm{min}$, hold temperature and time of $550^{\circ} \mathrm{C}$ and $30 \mathrm{~min}$, respectively, and a constant helium flow of $30 \mathrm{~mL} / \mathrm{min}$. Stainless-steel capsules were used to suppress volatile loss and sample degradation during assays.

Precondition of the samples was as follows: samples of about $10 \mathrm{mg}$ were removed for testing after a predefined immersion time (90 days) and kept in a sealed environmentally controlled container, at a constant temperature $\left(4^{\circ} \mathrm{C}\right)$, and were allowed to dry until constant weight. Equilibrium hydration degree was considered when no weight change (0.01 g) was observed. Starch-based materials can absorb different amounts of water when immersed in solution. From experiences with the three batches, SEVA-C squared plates can absorb 5.8\%, two films 5.3\%, and four films $4.5 \%$. Samples were introduced in standard stainless steel capsules before starting the tests. Assays were performed in three duplicates, considering the average of all the results as the final result.

Standards of starch and glycerol were also used using the same experimental conditions. Comparison between TGA data of standards and squared plate/films of SEVA-C suggests the occurrence of three weight loss processes: below $230^{\circ} \mathrm{C}$ (glycerol), between 230 and $345^{\circ} \mathrm{C}$ (starch), and above $345^{\circ} \mathrm{C}$ (EVAL). This method was applied to give a qualitative idea of the degradation product after enzymatic activity and not to quantify the analysis of these products. ${ }^{34}$

Contact angle measurements and surface free energy determinations. The effect of the degradation solution on untreated and enzyme treated SEVA-C surface specimens and films, as a function of the immersion time, was followed by contact angle measurements to investigate any changes in the wettability of the surface materials. Using contact angles of formamide $\left(\theta_{\mathrm{F}}\right)$, water $\left(\theta_{\mathrm{w}}\right)$, and diiodomethane $\left(\theta_{\mathrm{D}}\right)$ and surface tension components of each liquid, the following equation system was used to determine the surface free energy and the respective importance of polar and dispersive contributions ${ }^{35}$ :

$$
\begin{aligned}
& \gamma_{s}^{L W}=12.7\left(1+\cos \theta_{\mathrm{D}}\right)^{2} \\
& 5.049 \sqrt{\gamma_{\mathrm{s}}^{+}}+5.049 \sqrt{\gamma_{\mathrm{s}}^{-}}=36.4\left(1+\cos \theta_{\mathrm{w}}\right)-16.639\left(1+\cos \theta_{\mathrm{D}}\right) \\
& 6.293 \sqrt{\gamma_{\mathrm{s}}^{+}}+1.510 \sqrt{\gamma_{\mathrm{s}}^{-}}=29\left(1+\cos \theta_{\mathrm{F}}\right)-22.255\left(1+\cos \theta_{\mathrm{D}}\right)
\end{aligned}
$$

where: $\gamma_{\mathrm{s}}^{\mathrm{LW}}$ - non-polar component of the surface tension and $\gamma_{s}^{+}, \gamma_{s}^{-}$- polar components of surface tension.

Plates and films surfaces were cleaned and dried at $80^{\circ} \mathrm{C}$ for 1 week and kept in a desiccator. These measurements were carried out at room temperature, in a standard contact angle apparatus (Dataphysics, model OCA 20), using
TABLE I. Surface Tension Parameters, Polar and Disperse Components of Probe Liquids ${ }^{31}$ in $\mathrm{mN} / \mathrm{m}$

\begin{tabular}{llrrr}
\hline Liquid & $\gamma^{\text {TOT }}$ & $\gamma^{\text {LW }}$ & \multicolumn{1}{c}{$\gamma^{+}$} & \multicolumn{1}{c}{$\gamma^{-}$} \\
\hline Water & 72.8 & 21.8 & 25.5 & 25.5 \\
Diiodomethane & 50.8 & 46.6 & 0.0 & 4.2 \\
Formamide & 58.0 & 39.0 & 2.3 & 39.6 \\
\hline
\end{tabular}

the sessile drop technique, with a video camera mounted on a microscope to record the drop image. Sessile drops were deposited with a micrometric syringe directly on the surface from the metallic needle.

Surface free energy was calculated by using the Van Oss method. ${ }^{35}$ The surface free energy parameters of these liquids are listed in Table I.

Measurements were recorded $40 \mathrm{~s}$ after contact with the surface (depending on the material, specimen or film), removing the initial values, where major changes may occur. Laplace-Young method was used to record angle values.

At least 10 drops of about $4 \mu \mathrm{L}$ for each liquid were performed for each sample analyzed. Results are expressed as mean \pm standard deviation.

SEM. Modifications on the surface morphology and interconnectivity of SEVA-C specimens and films with enzymatic physiological solution, as a function of immersion time, were characterized by SEM in a Leica Cambridge S360 microscope. Before analysis, plates and films were cleaned and dried at $50^{\circ} \mathrm{C}$ for 1 week and kept in a desiccator. Specimen without enzymes was used as control.

The microstructure was also studied on samples (specimens of starch, SEVA-C and films) without enzymes and after enzymatic degradation, after boiling $\sim 0.2 \mathrm{~g}$ of materials (square plates and films) and starch in $150 \mathrm{~mL}$ of distilled water, under stirring for $5 \mathrm{~h}$, to simulate final degradation conditions. SEVA-C powder was used, as it was more easily dissolved. The samples were freeze dried in a Freeze Dryer Alpha 2-4. The resulting powders were conditioned in a desiccator before SEM analysis.

AFM. To observe the surface and roughness properties of SEVA-C specimens and films, as a function of the immersion time, a NanoScope III atomic force microscope was used.

SEVA-C discs of $10 \mathrm{~mm}$ diameter and $1 \mathrm{~mm}$ thickness were used. Before analysis, specimens were cleaned with acetone, rinsed with distilled water, dried at $50^{\circ} \mathrm{C}$ for 1 week, and stored in desiccators under constant relative humidity. A nonimmersed specimen stored at controlled environment conditions was used as control.

The in situ observation was performed in tapping mode. The lateral scanning movement of the tip occurs above the surface so that it only touches the surface for a very small fraction of its oscillation. A silicon tip was used. All the images were recorded with a scan size of $10 \times 10 \mu \mathrm{m}$ and a data scale $1500 \mathrm{~nm}$. 


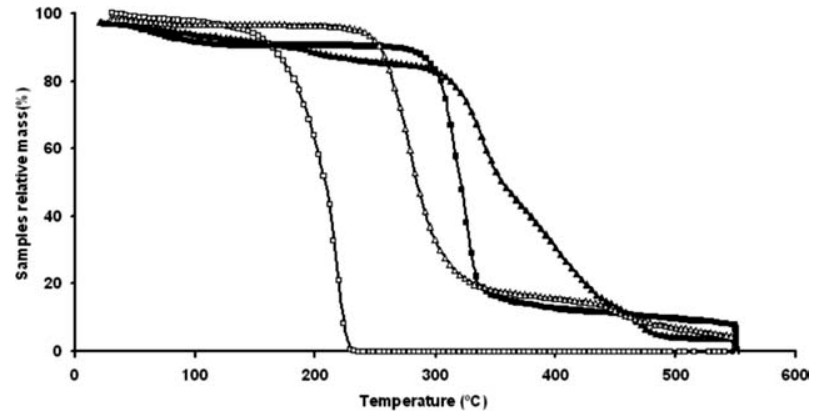

FIGURE 3. Thermogravimetry results on EVAL ( $\square$ ), glycerol ( $\square$ ), SEVA-C $(\mathbf{\Delta})$ and $\operatorname{starch}(\triangle)$ relative mass loss vs. temperature. Each point is the mean value of the results.

\section{RESULTS}

Surface properties are critical to the implant functional behavior of degradable polymeric materials as degradation may proceed initially on surface materials. Hydrophilicity is also a determining parameter in the degradation behavior of starch-based biomaterials that influences the spreading and interactions on the surface topography.

\section{TGA of SEVA-C blends}

TGA results of SEVA-C and standards are shown in Figure 3. Data show three main features corresponding to each component of the blend (glycerol, starch and EVAL): the complete volatilization of the glycerol below $230^{\circ} \mathrm{C}$, the pyrolysis of starch between 230 and $345^{\circ} \mathrm{C}$, and the pyrolysis of EVAL above $345^{\circ} \mathrm{C}$.

Weight loss vs. temperature for SEVA-C squared plates and films for different immersion times $(2,30$, and 60 days $)$ are shown in Figures 4 and 5.

Figure 6 summarizes degradation of starch vs. ageing for SEVA-C squared plates and films. Weight loss of the blend at a fixed temperature was obtained as the result of the superposition of weight losses of the pure components between 230 and $345^{\circ} \mathrm{C}$ (starch).

\section{Glycerol leached to the solution}

Figure 7 shows the results of glycerol leached to the solution after degradation periods. No significant differences were detected between square plates and films. The values

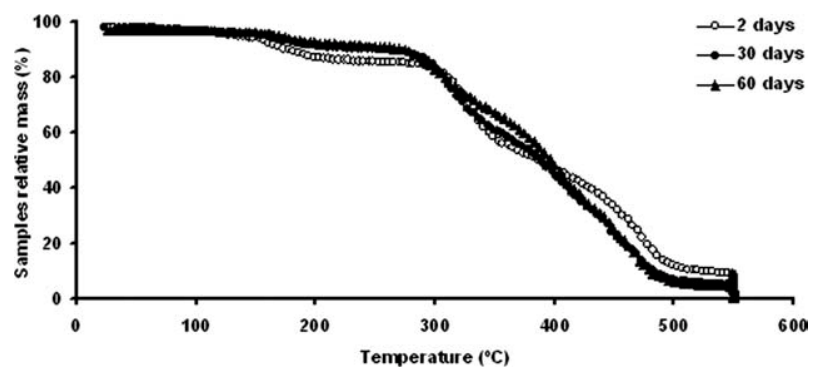

FIGURE 4. TGA data relative mass loss vs. temperature on SEVA-C squared plate for different immersion times. Each point is the mean value of the results.

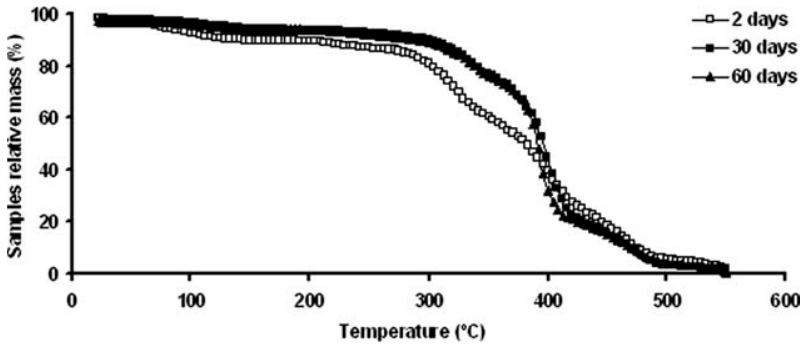

FIGURE 5. TGA data relative mass loss vs. temperature on SEVA-C four films for different immersion times. Each point is the mean value of the results.

were between 3 and $4 \%$ of mass of glycerol released per initial specimen mass.

Contact angle measurements and surface free energy on SEVA-C materials

When considering applications in the biomedical field, interfacial properties of the blends in contact with hydrated media are important in predicting interactions of the materials with the surrounding tissues.

One of the most usual methods to study the hydrophylicity and surface tension is the sessile drop technique, allowing the quantification of materials changes in terms of surface energy and the respective importance of polar and dispersive contributions.

Changes on SEVA-C squared plates and films surface hydrophilicity as a function of enzymatic degradation were evaluated using nonpolar and polar liquids: water, formamide, and diiodomethane. Figure 8 shows the results of contact angle measurements using water as test liquid.

Values of hydrophobic energy $\left(\Delta G_{\text {sws }}^{\mathrm{TOT}}\right)$ quantifies the hydrophilicity of the surfaces. Figures 9 and 10 depict polar $\left(\Delta G_{\mathrm{sws}}^{\mathrm{AB}}\right)$ and nonpolar $\left(\Delta G_{\mathrm{sws}}^{\mathrm{LW}}\right)$ components of free interfacial energy of SEVA-C surface squared plate and films as a function of immersion time.

\section{Surface morphology by SEM}

Qualitative changes on SEVA-C surface morphology in contact with the enzymatically active solution as a function of time were followed by SEM. Figure 11 shows SEVA-C squared plates and films micrographs after 90 immersion days.

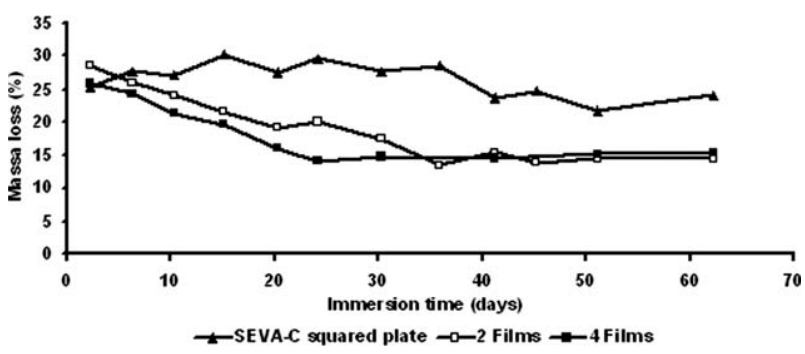

FIGURE 6. Starch degradation differences between 230 and $345^{\circ} \mathrm{C}(\%)$ vs. immersion time between SEVA-C squared plate and films. Each point is the mean value of the results. 


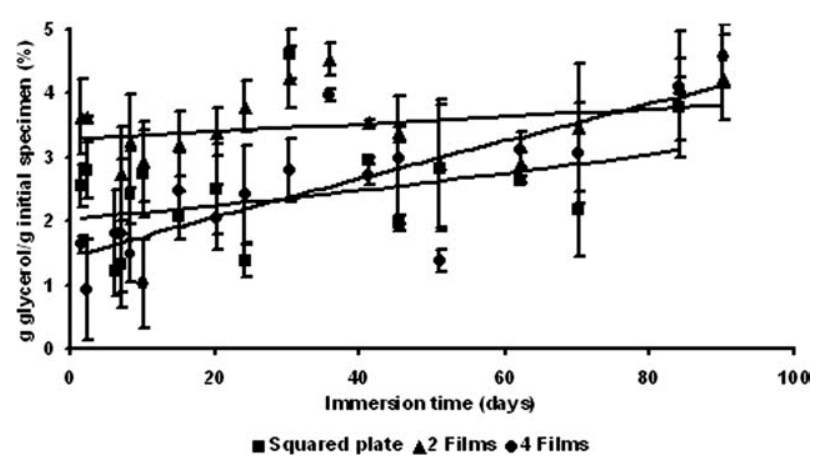

FIGURE 7. Mass of glycerol released to solution with 50 unit/l $\alpha$-amylase, per initial specimen (squared plates and films) mass (1.6 g) in 50 $\mathrm{mL}$ of solution, as a function of immersion time. Each point is the mean of two duplicates (four values in all); error bars are $95 \%$ confidence intervals of each mean.

Characterization also includes microstructure evaluation of SEVA-C squared plates and films by SEM, after boiled for different degradation times. The main objective was to analyze changes in internal microstructure after total destruction of the materials (Fig. 12).

\section{Surface morphology by AFM}

Figure 13 show the results of AFM images. AFM tapping mode topographic images show large morphological changes between control and more degraded samples $(90$ days), associated to increased surface porosity and root mean square roughness from hydrolytic dissolution of the materials.

\section{DISCUSSION}

As the TGA shows polymers of SEVA-C blend have distinct degradation temperature ranges (Fig. 3), enabling the use of thermogravimetric data to estimate their composition.

SEVA-C losses starch at a slightly higher temperature than native starch (Fig. 3); this shift is expected to be associated to the interpenetrating network structure of the blend.

SEVA-C squared plate (Fig. 4) shows differences for 60 immersion days on starch range degradation, between 230 and $345^{\circ} \mathrm{C}$. For other degradation periods, 2 and 30 days, no differences were detected, as being less degraded. For films (Fig. 5), between 30 and 60 immersion days no differ-

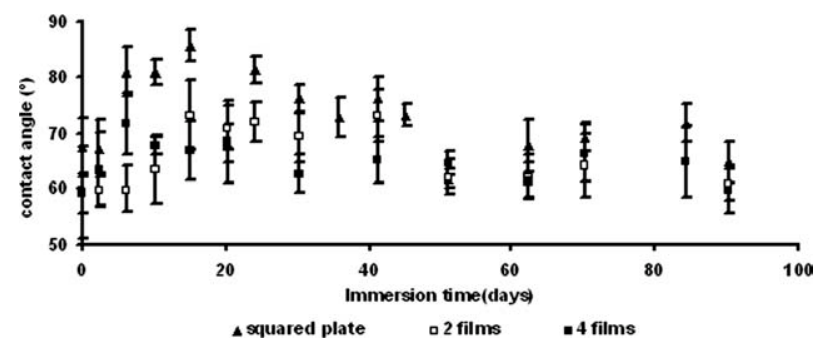

FIGURE 8. Contact angle measurements on SEVA-C surfaces vs. immersion time, using water as test liquid (measurements on dry samples). Error bars are $95 \%$ confidence intervals of each mean.

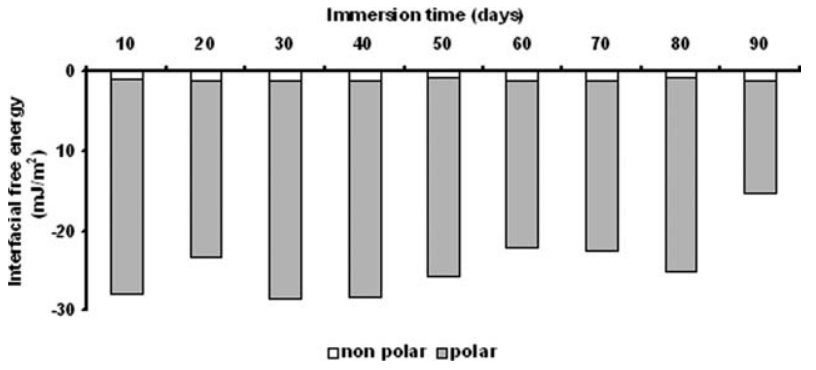

FIGURE 9. Nonpolar $\left(\Delta G_{\mathrm{sws}}^{\mathrm{LW}}\right)$ and polar $\left(\Delta G_{\mathrm{sws}}^{\mathrm{AB}}\right)$ components of free hydrophobic energy on SEVA-C squared plate surface vs. immersion times.

ence was observed as far as the starch phase was concerned.

As observed on Figure 6, SEVA-C squared plate shows greater percentage of remaining starch $(\sim 25 \%)$, thus less degraded than in the films that tended to stabilized towards a fixed value of about $10 \%$ of degradation, until the 90 immersion days. As already referred TGA was used as a qualitative method to evaluate differences between multicomponent systems of SEVA-C films, not to quantify the differences as this was already available on other studies. ${ }^{34}$

As a possible mechanism, only part of the starch phase was released and degraded in the solution, the other part remaining in the blend structure, as the enzymes can not reach the starch molecules strongly interpenetrated in the insoluble synthetic component. According with corn starch structure $(70 \%$ amylopectin and $30 \%$ amylase) one possible mechanism is the leaching of amylopectin fraction from the corn starch to the surface (which has many non-reducing end groups) where it can be degraded enzymatically whereas the amylose portion of the starch is tightly bound in the bulk.

This is also based on SEM images where the structural forms a microdispersion of microspheres of the two compounds difficult to reach by the enzymes (Fig. 12).

The diverse surface area of the squared plates and films leads to different values of starch phase released, although the materials had the same weight (1.6 g). No differences were detected between 2 and 4 thick mm films concerning starch degradation, tending towards the same value of $10 \%$.

As observed on Figure 7, the leaching of glycerol to the solution increased in the first days, stabilizing thereafter,

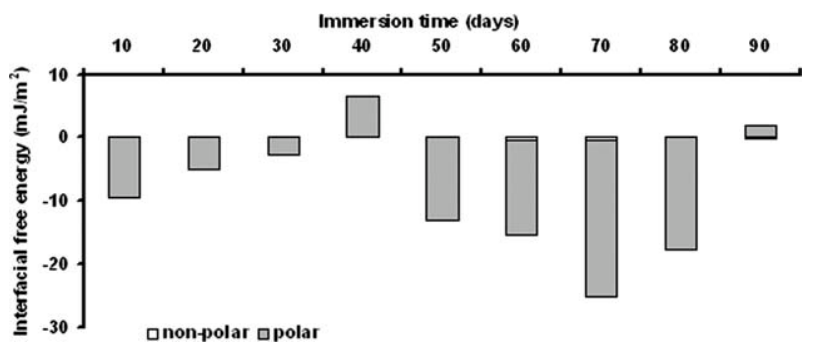

FIGURE 10. Nonpolar $\left(\Delta G_{\mathrm{sws}}^{\mathrm{LW}}\right)$ and polar $\left(\Delta G_{\mathrm{sws}}^{\mathrm{AB}}\right)$ components of free hydrophobic energy on SEVA-C four films surface vs. immersion times. 

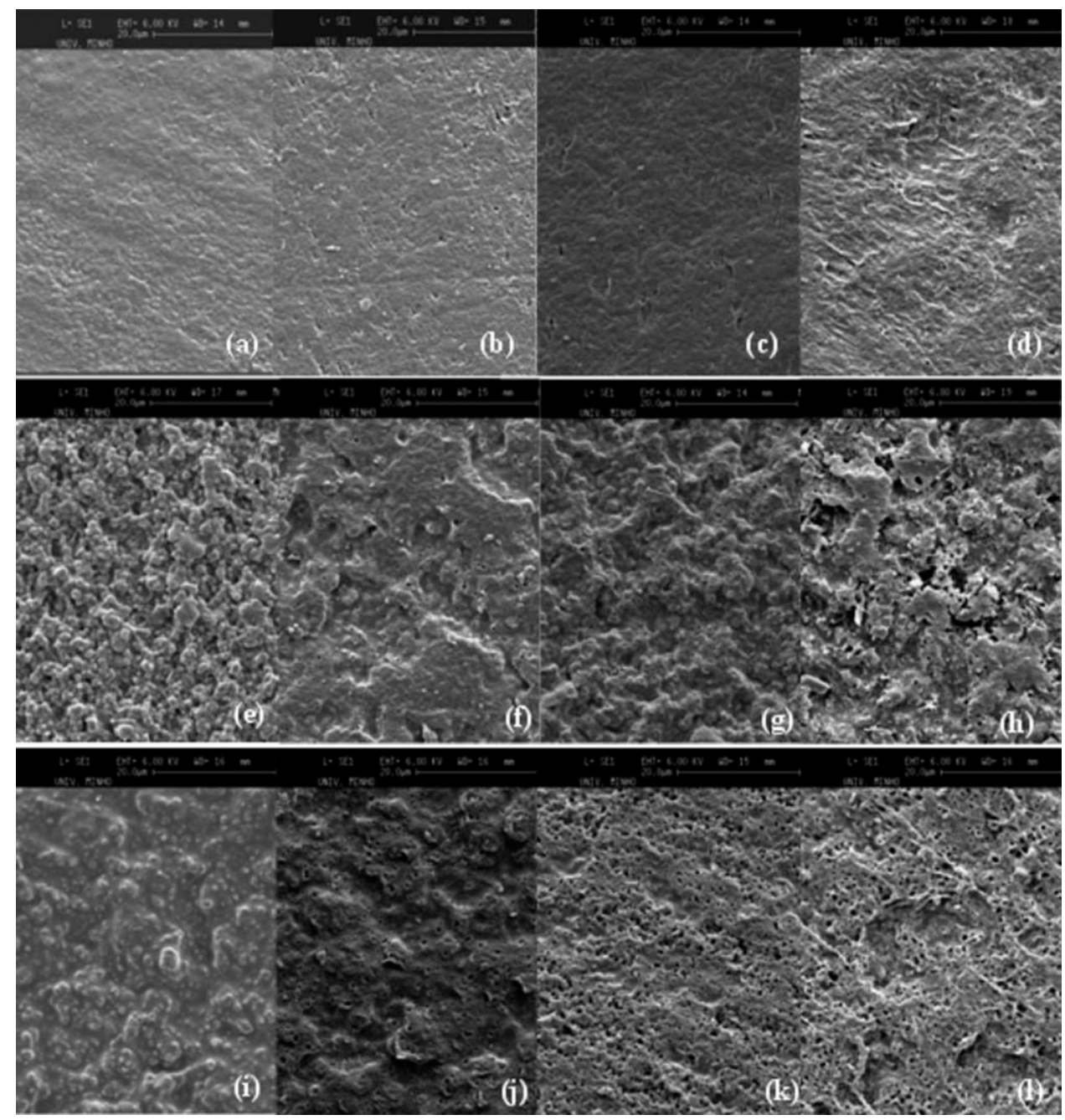

FIGURE 11. SEM micrographs of SEVA-C surfaces of control (without enzymes), after 10, 50, and 90 immersion days, respectively ( $\times 1500$ ). (a), (b), (c), (d) squared plate; (e), (f), (g), (h) two films; and (i), (j), (k), (l) four films. The images represent dried samples after immersion periods.

without any significant loss of weight, until the end of the assay. When in solution, the glycerol moves away from the material by hydrolysis, being completely soluble as it has no interaction with the copolymer. As expected, this process is followed by the material embrittlement as a result of the glycerol release. The values were between 3 and $4 \%$ of mass of glycerol released per initial specimen mass, as it is the same material, SEVA-C.

The plasticizer volatilization (glycerol), was also qualitative measured by TGA (below $230^{\circ} \mathrm{C}$ ) for all the batches, as Figures 4 and 5 showed.

Contact angle measurements using water as test liquid (Fig. 8) were higher than $50^{\circ}$, revealing wetting character of SEVA-C (contact angles around $40^{\circ}$ to $86^{\circ}$ are thus hydrophilic). Based on Figure 8, SEVA-C have deviated contact angle values due to surface roughness and porosity.

Squared plates exhibited higher hydrophobicity. This difference between the squared plates and films may be attributed to the following features: higher surface roughness, less starch availability on the outer surface (squared plates) and increased porosity (confirmed by SEM ands AFM results). These results are a consequence of the diverse surface between square plates and films that leads to different degradation process, despite the same material mass. Extrusion process to produce film samples could also interfere on surface morphology. For longer immersion periods contact angles tended to decrease, increasing surface hydrophilicity, as an effect from changes on functional groups from the outer surface and porosity/roughness surface modifications.

As depicted on Figures 9 and 10 polar component was higher on all the surfaces, interaction between surfaces and liquid was predominantly polar character. SEVA-C hidrophylicity surfaces decreases as: squared plates $>4$ films.

Figure 11 shows SEM micrographs of SEVA-C surfaces and it is possible to observe that squared plate surface microstructure is completely different from films. This is also confirmed on control samples. Extrusion process to produce film samples could also interfere on surface morphology. Section of the samples was also observed but no changes were observed as enzyme acts directly on the surface.

Porosity and roughness surfaces increased as a function of immersion time. Great differences were detected on 

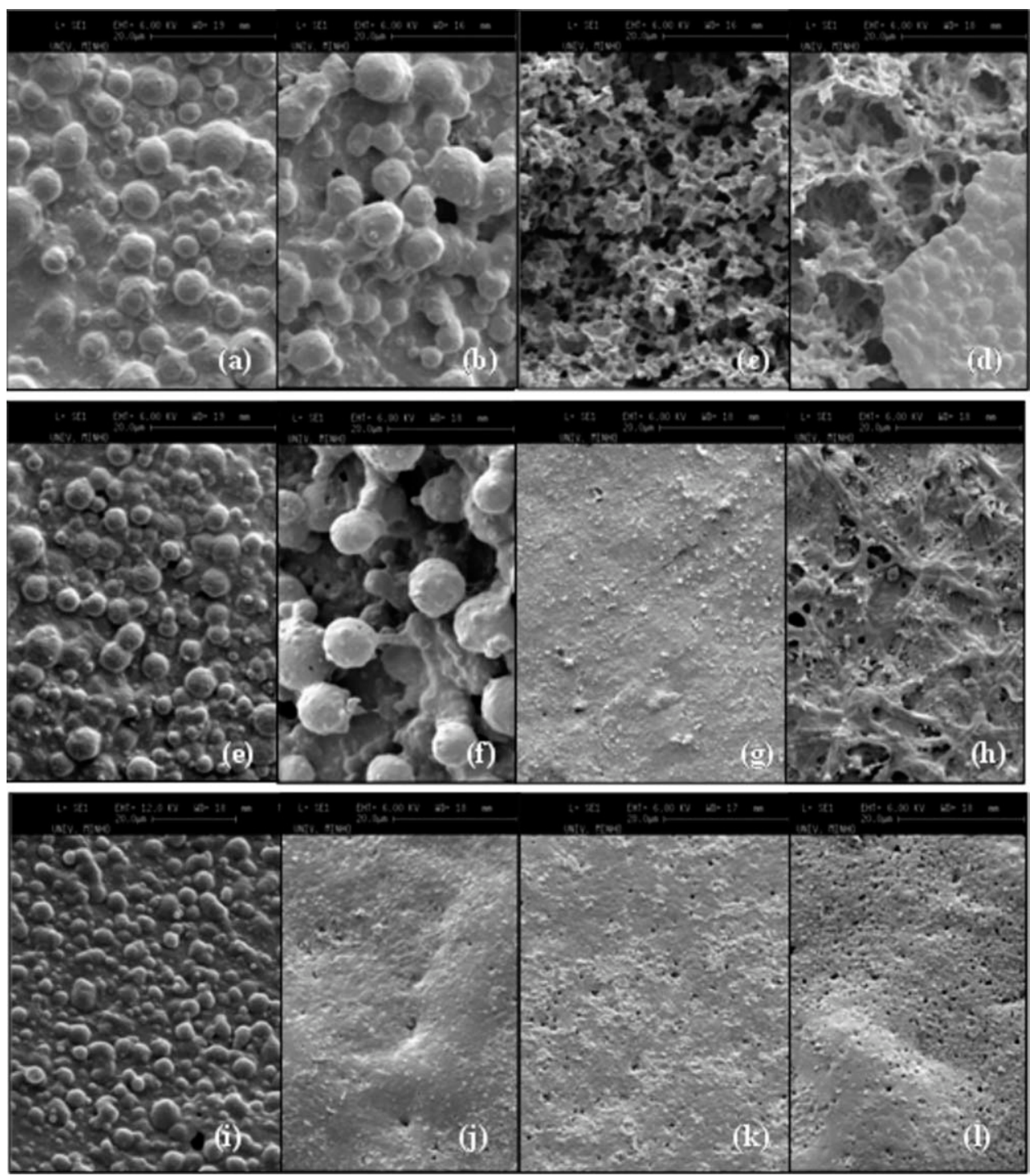

FIGURE 12. SEM micrographs of SEVA-C surfaces after boiling in distilled water for $5 \mathrm{~h}$ on control, after 20, 50 , and 90 immersion days, respectively ( $\times 1500)$. (a), (b), (c), (d) squared plate; (e), (f), (g), (h) two films; and (i), (j), (k), (l) four films. The images represent freeze-dried samples after boiling.

surface microstructure and texture between control (smooth) and more degraded samples (90 days), being more pronounced on films (rough). This phenomenon should be related to a hydrolytic surface dissolution of the original sample. Degradation may lead to loss of low molecular weight material enhancing the micro porosity of the materials. The removal of part of starch from SEVA-C polymeric blend should create a connected network of pores and formation of fractures, which would allow transport of enzyme to the interior of the material. This is a possible mechanism of enzymatic action on the surface that conducts to surface changes on the material. The enzymatic hydrolysis can also be limited by the enzyme size before penetration towards the inner of the material. Enzyme may act previously on surface material, increasing the number and size of pores as a result of chain scission.

Micrographs in Figure 12 show great differences between SEVA-C squared plates and films. After 50 days, the microstructure of squared plates was partially degraded, following starch phase destruction, evidencing great pores on surface structure. For 90 immersion days, it was possible to observe degraded zones with large holes and pores and granular zones not degraded. On films degradation process was faster, after 20 immersion days the surface was smooth without granules, losing almost all the starch phase, starch might be more easily available to enzymatic activity.

The observed granular structure may correspond to starch granules, which after degradation are surrounded by non-degraded EVOH chains, forming a dispersion of microspheres, due to the ability of starch to generate hydrophobic interactions with ethylene vinyl alcohol copolymers (EVAL). ${ }^{36}$

Using AFM tapping mode topographic images, small protrusions and voids were observed on more degraded surface blends (Fig. 13). Scale roughness varies accordingly with specimens (squared plates and films), where there were peaks/valleys with dimensions out of the normal range. 

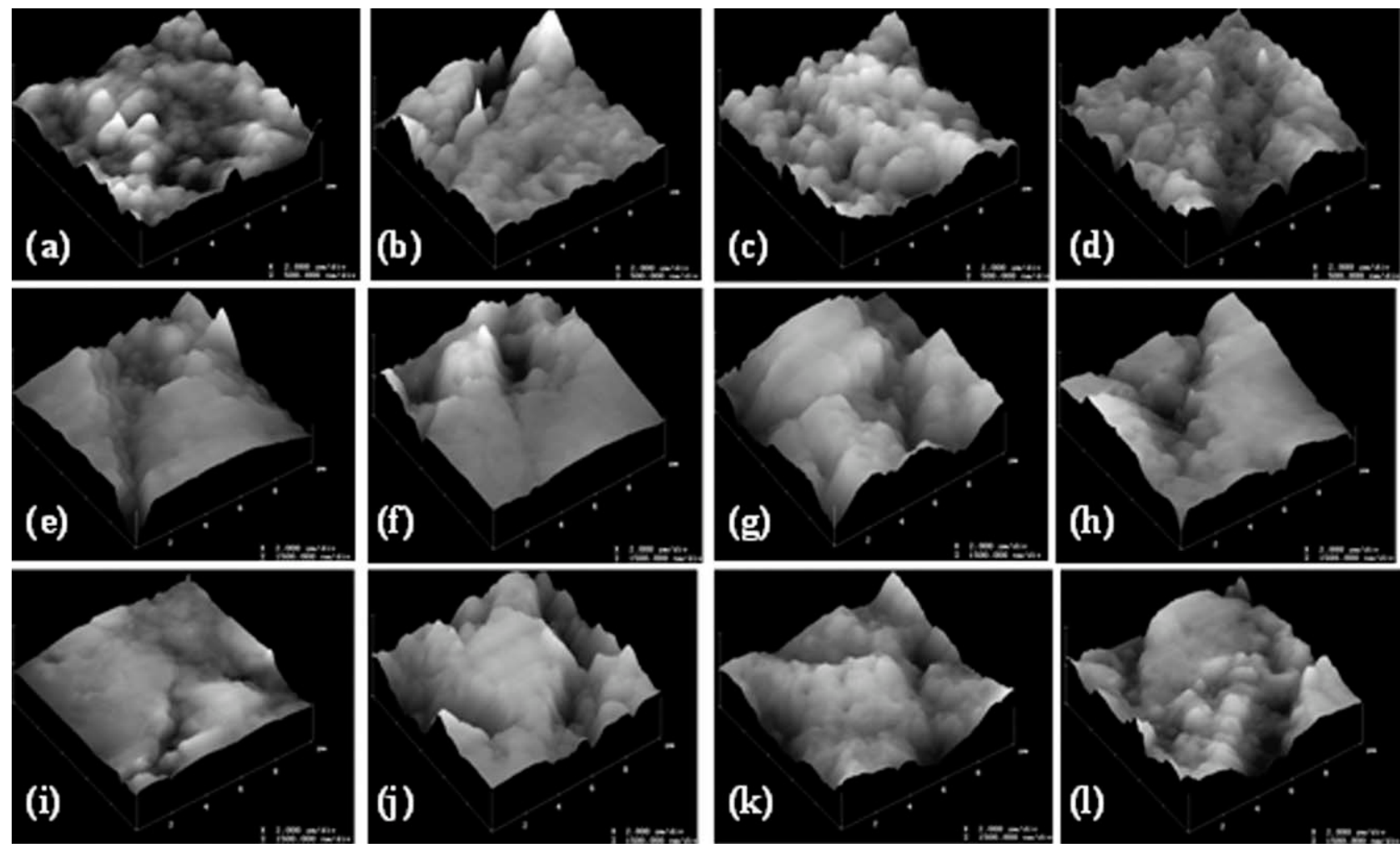

FIGURE 13. AFM tapping modes images of SEVA-C surfaces on control, after 30, 60, and 90 immersion days, respectively ( $\times 1500)$. (a), (b), (c), (d) squared plate; (e), (f), (g), (h) two films; and (i), (j), (k), (I) four films. The images represent dried samples after immersion periods.

\section{CONCLUSIONS}

To study the morphological changes on the biodegradation mechanism when starch based materials are immersed on simulated physiological solution, different experiences were performed using SEVA-C of different thickness.

The morphological surface analysis performed on SEVA$\mathrm{C}$ with different thickness (different exposed surface) after ageing on simulated physiological solution with enzymatic activity, led to the following conclusions:

The kinetic parameters of the amylase enzymatic degradation, for this specific environment of vinyl alcohol and suspended starch are not affected by the presence of organic phase. The results also suggest that the presence of other constituents in the compound, such as glycerol, also do not affect the kinetic parameters.

Accordingly, and as the plates of different thickness were obtained from the same raw-material, it should be included that the observed different in the enzyme degradation kinetics, are controlled by diffusion mechaninsms.

- Hydrolysis of starch from the internal microstructure leads to an increase in surface porosity, pore size, roughness and pore structure as was confirmed by SEM and AFM. This phenomenon should be related to the hydrolytic surface dissolution of the original sample.

- SEM micrographs after boiling evidenced a structure of a dispersion of microspheres, due to the ability of starch to generate hydrophobic interactions with ethylene vinyl alcohol copolymers (EVAL). This structure may limit the inner and external diffusion and transport mass of starch.

- SEVA-C surfaces were wetting, since average contact angles measurements with water were higher than $50^{\circ}$. This character was more pronounced in the films.

- According with TGA results the degradation process tends to stabilize at a final value and no differences were observed between SEVA-C 2 and 4 films, although they present different exposed surface. The thickness limit is around $0.5 \mathrm{~mm}$ (2 films), according with previous results.

- The minimum thickness limit to ensure maximum degradation may be estimated to be close to $0.25 \mathrm{~mm}$ (half of the $0.5 \mathrm{~mm}$ film thickness), according with the three batches performed. Degradation rate depends directly on the exposed surface.

Polymeric structure blends also influences the rate of enzymatic hydrolysis by limiting accessibility of enzymes to the inner starch substrate.

As a conclusion further optimization and control of the main physical material properties appropriate to enzymatic degradation processes on specific applications, depends on material thickness (surface structure), surface porosity and roughness, limiting thus the in vivo resorption. The rate of degradation can be easily tailored by means of proper choice of these parameters to attain very distinct properties, which provide for several different applications. 
Although, the released products could be metabolized and excreted by normal human mechanism, being necessary to perform in vivo assays to confirm particle resorption and their behavior in temporary tissue replacement applications.

\section{REFERENCES}

1. Andriano KP, Pohojen $T$, Tomalla P. Processing and characterization of absorbable polylactide polymers for use in surgical implants. J Appl Biomater 1994;5:133-140.

2. Hayashi T. Biodegradable polymers for biomedical uses. Prog Polym Sci 1994;19:663-702.

3. Pachence JM, Kohn J. Biodegradable polymers in tissue engineering. In: Lanza R, Langer R, Chick W, editors. Principles of Tissue Engineering. New York: Academic Press; 1997. p 263-272.

4. Farrar DF Gillson RK. Hydrolytic degradation of polyglyconate B: relationship between degradation time, strength and molecular weight. Biomaterials 2002;23:3905-3912.

5. Anderson JM, Zhao QH. Biostability of biomedical polymers. MRS Bulletin 1991;16:75-77.

6. Reis RL, Cunha AM. Characterization of two biodegradable polymers of potential application within the biomaterials field. J Mater Sci Mater Med 1995;6:786-792.

7. Leonor IB, Kim HM, Balas F, Kawashita M, Reis RL, Kokubo T, Nakamura T. Alkaline treatments to render starch-based biodegradable polymers self-mineralizable. J Tissue Eng Regen Med 2007;1:425-435.

8. Elizabeth RB, Kadriye T, Alexandra PM, Helena SA, Rui RL. A novel enzymatically-mediated drug delivery carrier for bone tissue engineering applications: Combining biodegradable starchbased microparticles and differentiation agents. J Mater Sci Mater Med 2008;19:1617-1623.

9. Pashkuleva I, Azevedo HS, Reis RL. Surface structural investigation of starch-based biomaterials. Macromol Biosci 2008;8: 210-219.

10. Otey FH, Doane WM. Chemicals from starch. In: Whistler RL, Otey FH, Doane WM, editors. Starch Chemistry and Technology, 2nd ed. New York: Academic Press; 1984. p 154-155.

11. Espigares I, Elvira C, Mano JF, Vazquez B, San Roman J, Reis RL. New partially degradable and bioactive acrylic bone cements based on starch blends and ceramic fillers. Biomaterials 2002;23: 1883-1895.

12. Malafaya PB, Elvira C, Gallardo A, San Roman J, Reis RL. Porous starch-based drug delivery systems processed by a microwave route. J.Biomater Sci Polym Edn 2001;12:1227-1241.

13. Pereira CS, Vásquez $B$, Cunha AM, Reis RL, San Roman J. New starch-based thermoplastic hydrogels for use as bone cements or drug-delivery carriers. J Mater Sci Mater Med 1998;19:825-833.

14. Reis RL, Cunha AM, Allan PS, Bevis MJ. Structure development and control of injection-molded hydroxylapatite-reinforced starch/ EVOH composites. Adv Polym Technol 1997;16:263-277.

15. Reis $R L$, Cunha AM. New degradable load-bearing biomaterials composed of reinforced starch based blends. J Appl Med Polym 2000;4:1-5.

16. Reis RL, Cunha AM, Allan PS, Bevis MJ. Mechanical behavior of injection-molded starch-based polymers. Polym Adv Technol 1996;7:784-790.

17. Reis RL, Mendes SC, Cunha AM, Bevis MJ. Processing and in vitro degradation of starch/EVOH thermoplastic blends. Polym Int 1997;43:347-352.
18. Malafaya PB, Stappers F, Reis RL. Starch-based microspheres produced by emulsion crosslinking with a potential media dependent responsive behavior to be used as drug delivery carriers. J Mater Sci Mater Med 2006;17:371-377.

19. Gomes ME, Ribeiro AS, Malafaya PB, Reis RL, Cunha AM. A new approach based on injection moulding to produce biodegradable starch-based polymeric scaffolds: Morphology, mechanical and degradation behavior. Biomaterials 2001;22:883-889.

20. Gomes ME, Reis RL, Cunha AM, Blitterswijk CA, Bruijn JD. Cytocompatibility and response of osteoblastic-like cells to starchbased polymers: Effect of several additives and processing conditions. Biomaterials 2001;22:1911-1917.

21. Marques $A P$, Reis $R L$, Hunt JA. The biocompatibility of novel starch-based polymers and composites: In vitro studies. Biomaterials 2002:23:1471-1478.

22. Mendes SC, Reis RL, Bovell YP, Cunha AM, van Blitterswijk CA, de Bruijn JD. Biocompatibility testing of novel starch-based materials with potential application in orthopaedic surgery: A preliminary study. Biomaterials 2001;22:2057-2064.

23. Salgado AJ, Coutinho OP, Reis RL, Davies JE. In vivo response to starch-based scaffolds designed for bone tissue engineering applications. J Biomed Mater Res Part A 2007;80:983-989.

24. Yoshida Y, Uemura T. Biodegradable Plastics and Polymers. Amsterdam: Elsevier Science; 1994.

25. Bastioli C, Bellotti V, Camia M, Del GL, Rallis A, Biodegradable Plastics and Polymers. Amsterdam: Elsevier Science; 1994. p 200.

26. Bastioli C. Properties and applications of mater-bi starch-based materials. Polym Degrad Stab 1998;59:263-212.

27. Bastioli C, Bellotti V, Del Giudice L, Gilli G. Mater-Bi: Properties and biodegradability. J Environ Polym Degrad 1993;1:181-189.

28. Araújo A, Cunha AM, Mota M. Changes in morphology of starchbased prothestic thermoplastic material during enzymatic degradation. J Biomater Sci Polym Ed 2004;15:1263-1280.

29. Araújo MA, Cunha A, Mota M. Enzymatic degradation of starchbased thermoplastic compounds used in protheses: identification of the degradation products in solution. Biomaterials 2004;25: 2687-2693.

30. Boesel LF, Azevedo HS, Reis RL. Incorporation of alpha-amylase enzyme and a bioactive filler into hydrophilic, partially degradable, and bioactive cements (HDBCs) as a new approach to tailor simultaneously their degradation and bioactive behavior. Biomacromolecules 2006;7:2600-2609.

31. Zhang GY, Venkatachalam M, Hamaker BR. Structural basis for the slow digestion property of native cereal starches. Biomacromolecules 2006;7:3259-3266.

32. Hakkarainen M, Albertsson AC, Karlsson S. Weight losses and molecular weight changes correlated with the evolution of hydroxyacids in simulated in vivo degradation of homo- and copolymers of PLA and PGA. Polym Degrad Stab 1996;52: 283-291.

33. Miller GL. Use of dinitrosalicylic acid reagent for determination of reducing sugar. Anal Chem 1959;31:426-428.

34. Araújo MA, Cunha AM, Mota M. Enzymatic degradation of starch based thermoplastic blends using different thickness samples. J Mater Sci Mater Med 2009;20:607-614.

35. Van Oss CJ. Experimental measurement methods. Interfacial Forces in Aqueous Media. New York: Marcel Dekker; 1994. p 89161.

36. Bastioli C, Belloti V, Camia M, Del Giudice L, Rallis A. Starch/ vinyl-alcohol copolymer interactions. In: Doi Y, Fukuda K, editors. Biodegradable Plastics and Polymers. Amsterdam, The Netherlands: Elsevier Science; 1994. p 200-213. 